\title{
Cisplatin Inhibits AhR Activation
}

\author{
Erina Sasaki-Kudoh', Ikuru Kudo' ${ }^{2}$ Yuka Kakizaki', Miki Hosaka' ${ }^{2}$, Shun-Ichi Ikeda1, \\ Seiya Uemura ${ }^{2}$, Ewa Grave ${ }^{2}$, Shuntaro Togashi' ${ }^{1}$, Taku Sugawara ${ }^{3}$, Hiroaki Shimizu ${ }^{1}$, \\ Hideaki Itoh ${ }^{2 *}$
}

\author{
${ }^{1}$ Department of Neurosurgery, Akita University Graduate School of Medicine, Akita, Japan \\ ${ }^{2}$ Department of Life Science, Akita University Graduate School of Engineering Science, Akita, Japan \\ ${ }^{3}$ Department of Spinal Cord and Spine Surgery, Research Institute for Brain and Blood Vessels-Akita, Akita, Japan \\ Email: *itohh@gipc.akita-u.ac.jp
}

How to cite this paper: Sasaki-Kudoh, E., Kudo, I., Kakizaki, Y., Hosaka, M., Ikeda, S.-I., Uemura, S., Grave, E., Togashi, S., Sugawara, T., Shimizu, H. and Itoh, H. (2018) Cisplatin Inhibits AhR Activation. American Journal of Molecular Biology, 8, 69-82.

https://doi.org/10.4236/ajmb.2018.81006

Received: November 9, 2017

Accepted: January 23, 2018

Published: January 26, 2018

Copyright $\odot 2018$ by authors and Scientific Research Publishing Inc. This work is licensed under the Creative Commons Attribution International License (CC BY 4.0).

http://creativecommons.org/licenses/by/4.0/

\begin{abstract}
The AhR binds to contain ligands, such as 2, 3, 7, 8-tetrachlorodibenzo-p-dioxin, 3-methylcholantrene, or $\beta$-naphthoflavone. The activation mechanism of AhR is not yet fully understood, but it is known that AhR associates with the molecular chaperone HSP90 in the cytoplasm. There are a few reports about the association or dissociation of AhR and HSP90, and which domain of HSP90 binds to AhR. We reported the association and activation mechanisms between HSP90 and AhR-PAS or AhR-bHLH. In the current study, we found that cisplatin inhibits the AhR activation. Although ATP and 17-DMAG have no effect on the dissociation of HSP90 from AhR, some contents of HSP90 were dissociated from AhR in the presence of cisplatin. We could detect the increase of CYP1A in the presence of 3-MC. On the contrary, the induction of CYP1A1 was inhibited in the presence of cisplatin. We couldn't detect AhR in the HeLa cell soluble fraction in the presence of $50 \mu \mathrm{M}$ cisplatin. In the presence of MG-132, we could detect AhR. These results suggested that AhR was dissociated from the HSP90 chaperone complex and processed during the protein proteasome degradation system in the presence of cisplatin.
\end{abstract}

\section{Keywords}

Cisplatin, CDDP, AhR, Aryl Hydrocarbon Receptor, HSP90, 17-DMAG

\section{Introduction}

The molecular chaperone HSP90 is an essential protein in eukaryotic cells. It interacts with more than 300 proteins, and regulates the physiological function in the cell [1] [2]. HSP90 interacts with a cancer, and the inhibitor of HSP90 is ex- 
pected as an anticancer agent. 17-(Dimethylaminoethylamino)-17-demethoxygeldanamycin (17-DMAG) is one of the HSP90 inhibitors, and it inhibits the ATPase activity of HSP90. We reported that cisplatin, one of the anticancer agents, mainly binds to the $\mathrm{C}$-terminal and also the $\mathrm{N}$-terminal domain of HSP90 and inhibits the chaperon activity [3] [4].

The aryl hydrocarbon receptor (AhR) is the ligand-dependent transcriptional regulator that mediates the toxic effects of chemicals such as 2, 3, 7, 8-tetrachlorodibenzo-p-dioxin (TCDD), 3-methylcholanthrene (3-MC), and $\beta$-naphthoflavone $(\beta$-NF). It forms a complex with HSP90, co-chaperone $\mathrm{p} 23$, and the hepatitis B virus X-associated protein XAP2 in the cytoplasm [5]-[10]. After binding of a ligand, AhR is translocated into the nucleus and forms a complex with Arnt (AhR nuclear translocator). The AhR/Arnt heterodimer binds to the xenobiotic responsible element (XRE) and promotes the transcription of cytochrome P450 1A1 (CYP1A1), one of the xenobiotic metabolizing enzymes. Ligands of AhR cause toxicological effects, such as suppression of the immune response, impairment of reproduction, and promotion of carcinogenesis [11] [12].

AhR is composed of the basic helix-loop-helix (bHLH) domain and Per-ArntSim homology (PAS) domain. The bHLH domain is a motif participating in DNA binding, HSP90 binding, and dimerization. The PAS domain is a ligand binding domain. It is made from PAS-A and PAS-B, and HSP90 binds to the PAS-B. The glutamine (Q)-rich region is near the carboxyl-terminal of AhR [10]. Purification of the full-length AhR is difficult, and there are few studies that analyzed the direct interaction of HSP90 and AhR. Thus, we purified the AhR-PAS and AhR-bHLH domain, and analyzed the direct interaction of HSP90 and the AhR-PAS or AhR-bHLH domain in vitro.

Cisplatin (cis-Diamineplatium (II) dichloride) is a widely used antineoplastic drug for clinical cures. Cisplatin possesses the ability to bind DNA and inhibits the replication of DNA, resulted in the inhibition of tumor cell growth. Previously, we found that cisplatin directly binds HSP90 and inhibits its aggregation prevention activity in vitro [3]. Cisplatin inhibits glucocorticoid receptor-dependent and androgen receptor-dependent transcriptional activities in a dose-dependent manner in human cultured cells [13]. Inhibition of the HSP90 functions by cisplatin is considered to occur in vivo as well as in vitro. There is no report against the influence of cisplatin to AhR-HSP90 complex. We investigated the influence of cisplatin on the association or dissociation of AhR from HSP90-cochaperone complex.

\section{Materials and Methods}

\subsection{Chemicals}

17-(Dimethylaminoethylamino)-17-demethoxygeldamaysin as the inhibitor of HSP90 was purchased from Invitrogen (San Diego, U.S.A.). cis- Diamineplatium (II) dichloride as the inhibitor of HSP90 was purchased from SIGMA-ALDRICH (U.S.A.). Isopropyl-1-thio- $\beta{ }^{-}$-galactopyranoside (IPTG) was purchased from 
Nakarai Tesque. 3-Methylcholanthrene, and Dimethylsulfoxide (DMSO) from SIGMA; MG132 from PEPTIDE INSTITUTE.

\subsection{Antibodies}

An antibody against AhR and $\beta$-actin were from Thermo Fisher Scientific (catalogue no; MA1-513). The rabbit polyclonal antibodies against HSP90, XAP2, and p23 were previously described [3] [9] [10].

\subsection{Cell Culture}

The human cervical cancer cell line, HeLa cells were cultured in Dullbecco's modified Eagle's medium (DMEM; SIGMA) with 10\% fetal bovine serum (Equitech-Bio), $20 \mu \mathrm{g} / \mathrm{ml}$ streptomycin, and $20 \mathrm{unit} / \mathrm{ml}$ penicillin (GIBCO) at $37^{\circ} \mathrm{C}$ and $5 \% \mathrm{CO}_{2}$. For MG132 treatment, 20,000 cells were plated in 96 well E-plate and their growth was monitored for $24 \mathrm{~h}$. Cells were treated with $50 \mu \mathrm{M}$ cisplatin for $16 \mathrm{hr}$ and $50 \mu \mathrm{M}$ of MG132 was added for $1 \mathrm{~h}$ and fresh media was added following washing once with media.

\subsection{Cell Viability Assay}

Cells were cultured in 96-well plates at a density of 2500 per well in $100 \mu \mathrm{l}$ of medium $24 \mathrm{hrs}$ before addition of cisplatin. Cisplatin was added in concentrations of $0-100 \mu \mathrm{M}$. To assess cell viability, $10 \mu \mathrm{l}$ of MTT solution (Thiazolyl Blue Tetrazolium Bromide (SIGMA) $5 \mathrm{mg} / \mathrm{ml}$ in PBS (phosphate buffered saline $(-))$ was added after a $16 \mathrm{hrs}$ exposure to cisplatin. After a $4 \mathrm{~h}$ incubation, medium was removed and precipitates were lysed with $0.04 \mathrm{~N} \mathrm{HCl}$ in 2-propanol. Then, absorbance was measured using a plate reader (Infinite F200, Tecan) at $595 \mathrm{~nm}$.

\subsection{Cell Treatment}

HeLa cells were trypsinized and harvested in $35-\mathrm{mm}$ dishes at a density of $1.5 \times$ $10^{5}$ cells, allowed to adhere for $24 \mathrm{hrs}$. Then, cells were treated by addition of 2 $\mathrm{ml}$ fresh DMEM containing samples at desired concentrations in DMSO. The cells were incubated in a certain time at $37^{\circ} \mathrm{C}$ and $5 \% \mathrm{CO}_{2}$.

\subsection{Immunoblotting}

Cells were rinsed three times with cold PBS, and collected using cell scraper (iwaki). The cell lysates were centrifuged at $2000 \mathrm{rpm}$ at $4^{\circ} \mathrm{C}$ for $5 \mathrm{~min}$. The supernatants were removed and then lysed in lysis buffer (50 mM HEPES- $\mathrm{NaOH}$, 5\% Glycerol, 1\% NP-40, 5 mM EDTA, $100 \mathrm{mM} \mathrm{NaCl,} 1 \mathrm{mM}$ PMSF). After $10 \mathrm{~min}$ incubation on ice, the lysates were centrifuged at $15,000 \mathrm{rpm}$ at $4^{\circ} \mathrm{C}$ for 15 min and then the supernatants were used. Total protein concentrations of supernatants were determined by using BCA Protein Assay Kit (Thermo Fisher Scientific). Cellular proteins were separated by $7 \%$ (for AhR and HSP90) and 13\% (for XAP2 and p23) sodium dodecyl sulphate-polyacrylamide gel electrophoresis (SDE-PAGE), transferred onto PVDF membranes (BIO-RAD). Mem- 
branes were blocked by 3\% skim milk in TBS for $1 \mathrm{~h}$ at room temperature and proved with specific primary antibodies overnight at room temperature. AhR diluted 1:1000, $\beta$-actin diluted 1:3000, HSP90 diluted 1:1000, XAP2 diluted 1:500, p23 diluted 1:3000. Washing was twice for $5 \mathrm{~min}$ and membranes were proved with the secondary antibody for $1 \mathrm{~h}$ at room temperature. Anti-Rabbit IgG (whole molecule)-Alkaline Phosphatase against AhR, HSP90, XAP2, and p23 was diluted 1:2000. Anti-Mouse IgG (whole molecule)-Alkaline Phosphatase against $\beta$-actin was diluted 1:3000. Washing was twice for $5 \mathrm{~min}$ and membranes were detected by labeling with alkaline phosphatase. The protein contents were quantified using Image J software (Drop of Wisdom).

\subsection{Reverse Transcription-Polymerase Chain Reaction (RT-PCR)}

Total RNA was isolated from cells using RNeasy Mini Kit (Qiagen). First strand complementary DNA (cDNA) was synthesized from $4 \mu \mathrm{g}$ of total RNA with $\mathrm{Su}$ per Script III First-Strand (Invitrogen), and cDNAs were amplified with the following primers: CYP1A1 (forward, 5'-ACCACCAAGAACTGCTTAGCC-3'; reverse, 5'-GAAGAGTGTCGGAAG-3'), $\beta$-actin (forward, 5'-GCTCGTCGTCGA CAACGGCTC-3'; reverse, 5'-CAAACATGATCTGGGTCATCTTCTC-3'). $\beta$-actin (forward, 5'-GCTCGTCGTCGACAACGGCTC-3'; reverse, 5'-CAAACA TGATCTGGGTCATCTTCTC- ${ }^{\prime}$ ). The PCR products were separated in $1 \%$ agarose gels and stained with ethidium bromide. The CYP1A1/ $\beta$-actin ratio was quantified using Image J software (Drop of Wisdom).

\subsection{Recombinant Protein Contract, Expression and Purification}

The total RNA was isolated from the HeLa cells using the RNeasy Mini Kit (Qiagen, Valencia, CA). The amount and purity of the total RNA was estimated by spectrophotometric analysis at A260 and A280. The RNA quality was determined by agarose gel electrophoresis following ethidium bromide staining. Aliquots of the total RNA were diluted in diethylpyrocarbonated (DEPC)-treated water and stored at $-80^{\circ} \mathrm{C}$. RNA $(4 \mu \mathrm{g})$ was used to synthesize the first strand complementary DNA (cDNA) with Super Script III First-Strand (Invitrogen) under the following general conditions: denaturation at $94^{\circ} \mathrm{C}$ for 15 seconds, annealing at $55^{\circ} \mathrm{C}$ for 30 seconds, and extension at $68^{\circ} \mathrm{C}$ for 30 seconds for up to 40 cycles using an iCycler (BioRad). The cDNAs were PCR-amplified by iCycler (BioRad) with the primers of AhR [9] [10]. The AhR-bHLH domain was amplified by PCR (iCycler, BioRad) using the forward primer 5'-GTCGACATGGCT GAAGGAATCAAGTCAA-3' and reverse primer 5'-GCGGCCGCTCAATCA AAGAAGCTCTTGGCTCT-3'. The resulting PCR products were inserted into the SalI/NotI sites of the pGEX-5X-3 vector (Takara Bio, Japan). The constructs were confirmed by DNA sequencing (PRISM 3100, ABI). The AhR- $\triangle \mathrm{AD}$ domain was amplified by PCR (iCycler, BioRad) using the forward primer 5'-GTC GACATGAACAGCAGCAGCCGCCAAC-3' and reverse primer 5'-CTCGAG CTATTTTCGTAAATGCTCTGTTCC-3'. The resulting PCR products were in- 
serted into the SalI/XhoI sites of the pGEX-5X-3 vector (Takara Bio, Japan). The constructs were confirmed by DNA sequencing (PRISM 3100, ABI).

A full length cDNA of HSP $90 \alpha$ was kindly provided by Dr. Yokoyama (RIKEN, Japan). To generate the HSP90 recombinant protein expression, the HSP90 cDNA was amplified by PCR (iCycler, BioRad) using the forward primers 5'-GGATCCATGCCTGAGGAAACCCAGACC-3' and reverse primer 5'-TCTAGATTAGTCTAGTTCTTCCATGCG-3'. The resulting PCR products were inserted into the BamHI/XbaI sites of the pColdI vector (Takara Bio, Japan). The generated pColdI-HSP90 constructs were confirmed by DNA sequencing (PRISM 3100, ABI).

HSP90 and the GST-tagged AhR bHLH domain was expressed in previously reported [9] [10]. The GST-tagged AhR- $\triangle \mathrm{AD}$ domain was expressed in an Escherichia coli BL21 (DE3) Arctic Competent Cell (Stratagene). The cells were grown at $30^{\circ} \mathrm{C}$ in LB BROTH medium (Invitrogen) supplemented with 100 $\mu \mathrm{g} / \mathrm{ml}$ ampicillin for $3 \mathrm{hr}$, then cultured at $10^{\circ} \mathrm{C}$ for $30 \mathrm{~min}$. The cells were next induced by the addition of $0.5 \mathrm{mM}$ IPTG and the cultures were incubated at $10^{\circ} \mathrm{C}$ for an additional $24 \mathrm{hr}$. The cells were harvested by centrifugation at $20,000 \mathrm{xg}$ for $15 \mathrm{~min}$ at $4^{\circ} \mathrm{C}$, and the cell pellets were suspended in $10 \mathrm{mM}$ Tris-HCl, $\mathrm{pH}$ 7.4. The cells were sonicated, centrifuged at 20,000 $\mathrm{xg}$ for $10 \mathrm{~min}$ at $4^{\circ} \mathrm{C}$ and the formed pellets collected. The collected pellets were suspended in buffer (1 M Arginine, $10 \mathrm{mM}$ Tris- $\mathrm{HCl}$, $\mathrm{pH}$ 7.4), then dialyzed with $10 \mathrm{mM}$ Tris$\mathrm{HCl}, \mathrm{pH} 7.4$, overnight to remove the Arginine. After dialysis, the lysates were cleared by centrifugation at $20,000 \mathrm{xg}$ for $10 \mathrm{~min}$ at $4^{\circ} \mathrm{C}$. The supernatant was applied to glutathione columns (Glutathione Sepharose 4B, GE Healthcare Life Science), washed with $10 \mathrm{mM}$ Tris- $\mathrm{HCl}, \mathrm{pH} 7.4$, and then eluted with elution buffer (20 mM Glutathione, $10 \mathrm{mM}$ Tris- $\mathrm{HCl}, \mathrm{pH} 7.4$ ). The eluted proteins were concentrated by ultrafiltration.

\subsection{GST Pull-Down Assay}

For the GST pull-down assay, the concentration of ATP, 17-DMAG, and cisplatin were according to previous reports [9] [10]. $2.5 \mu \mathrm{M}$ GST-bHLH or GSTAhR- $\triangle \mathrm{AD}$ or GST protein was added to a solution of $2.5 \mu \mathrm{M}$ HSP90 in the presence or absence of $3 \mu \mathrm{M} 3 \mathrm{MC}, 50 \mu \mathrm{M}$ cisplatin, $50 \mu \mathrm{M}$ 17-DMAG, $1 \mathrm{mM}$ ATP and $150 \mu \mathrm{l}$ buffer A $\left(0.1 \mathrm{M} \mathrm{KCl}, 10 \mathrm{mM} \mathrm{MgCl}, 20 \mathrm{mM} \mathrm{Na}_{2} \mathrm{MoO}_{4}, 0.6 \mathrm{M}\right.$ $\mathrm{NaCl}, 5 \%$ Glycerol, $0.1 \% \mathrm{NP}-40$ in $25 \mathrm{mM}$ HEPES-KOH pH 7.4). The total volumes of the sample was $300 \mu \mathrm{l}$ by adding buffer B ( $5 \%$ Glycerol, $0.1 \%$ NP-40 in $25 \mathrm{mM}$ HEPES- $\mathrm{KOH} \mathrm{pH} \mathrm{7.4)} \mathrm{and} \mathrm{incubated} \mathrm{using} \mathrm{a} \mathrm{rotator} \mathrm{with} \mathrm{gentle} \mathrm{rotation}$ for $15 \mathrm{~min}$ at $37^{\circ} \mathrm{C}$. The samples were loaded onto a GST resin equilibrated with buffer C ( $50 \mathrm{mM} \mathrm{KCl}, 5 \mathrm{mM} \mathrm{MgCl}, 10 \mathrm{mM} \mathrm{Na}_{2} \mathrm{MoO}_{4}, 0.3 \mathrm{M} \mathrm{NaCl}, 5 \%$ Glycerol, $0.1 \% \mathrm{NP}-40$ in $25 \mathrm{mM}$ HEPES-KOH pH 7.4) and incubated for $15 \mathrm{~min}$ at $4^{\circ} \mathrm{C}$ with gentle rotation followed by spinning at $5000 \mathrm{rpm}$ for $10 \mathrm{sec}$ at $4^{\circ} \mathrm{C}$ to remove the supernatant. The beads were washed three times with buffer $\mathrm{C}$ and 
bound proteins were eluted by boiling at $100^{\circ} \mathrm{C}$ for $5 \mathrm{~min}$ in SDS sample buffer. All the GST pull-down samples were separated by SDS-PAGE (9\% or $11 \%$ gel) and detected by Coomassie Brilliant Blue R-250 staining.

\section{Results}

\subsection{Influence of Cisplatin on HeLa Cell Viability}

We investigated the effect of cisplatin on the HeLa cell viability. In the present study, we did the evaluation using human epitheloid cervix carcinoma HeLa cells. The cell viability was reduced to about $70 \%$ in a cisplatin dependent manner $(0-250 \mu \mathrm{M})$ (Figure 1). We focused on $50 \mu \mathrm{M}$ cisplatin in which the cell viability was about $80 \%$.

\subsection{Effects of Cisplatin on AhR and Chaperone Complex}

We analyzed the effects of cisplatin $(0-50 \mu \mathrm{M})$ on the contents of AhR, HSP90, XAP2, and p23 in the cells. No changes were observed for the proteins contents of HSP90, XAP2, and p23 on immunoblotting (Figure 2(a)). On the contrary, the contents of AhR were reduced at $50 \mu \mathrm{M}$ cisplatin. At $50 \mu \mathrm{M}$ cisplatin, about $80 \%$ of the AhR contents was reduced (Figure 2(b)). We investigated the effects of MG132 (proteasome inhibitor) on the AhR contents in the presence of cisplatin. In the presence of $50 \mu \mathrm{M}$ cisplatin, we could detect faintly AhR protein band in the absence of MG132. On the contrary, the AhR protein bands were clearly shown in the presence of $50 \mu \mathrm{M}$ cisplatin and MG132 (Figure 2(c)).

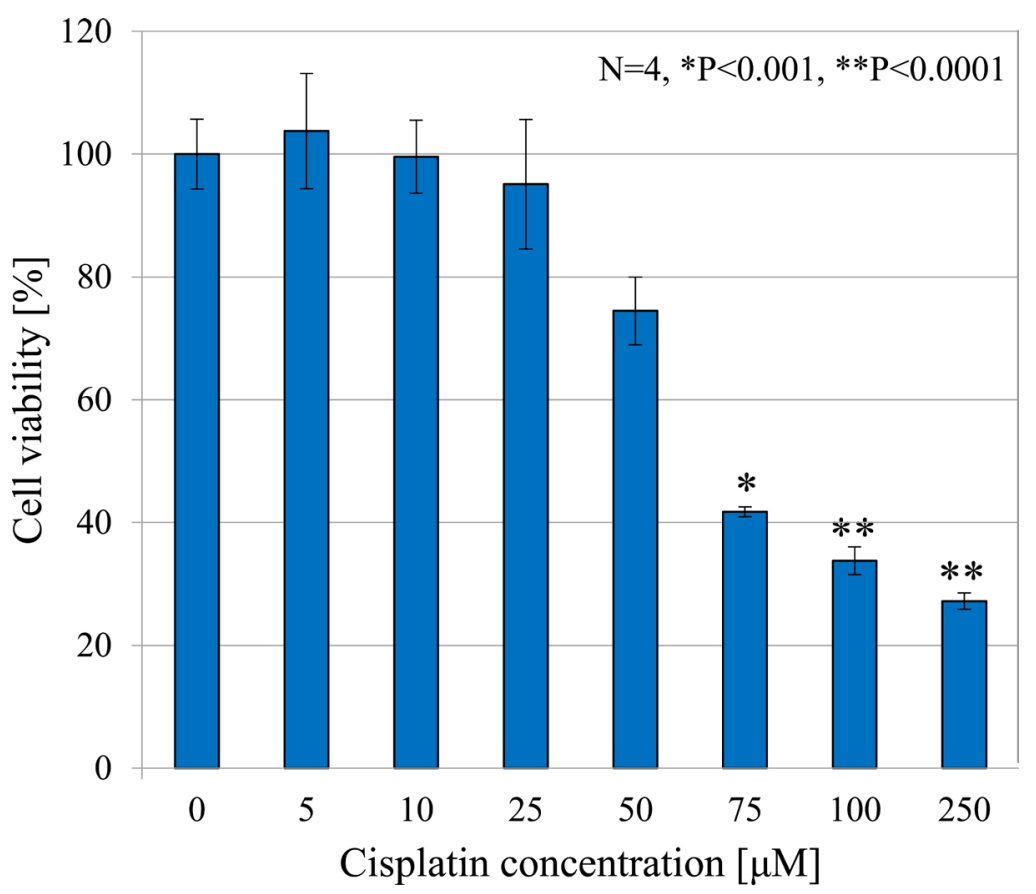

Figure 1. Effects of cisplatin on HeLa cell viability. HeLa cells were cultured in the presence or absence of cisplatin $(5-250 \mu \mathrm{M})$ for $16 \mathrm{hrs}$. The cell viability was measured using the MTT assay. The cell viability was about $80 \%$ at $50 \mu \mathrm{M}$ cisplatin. In the present study, we used $50 \mu \mathrm{M}$ of cisplatin. 
(a) Cisplatin $[\mu \mathrm{M}]$

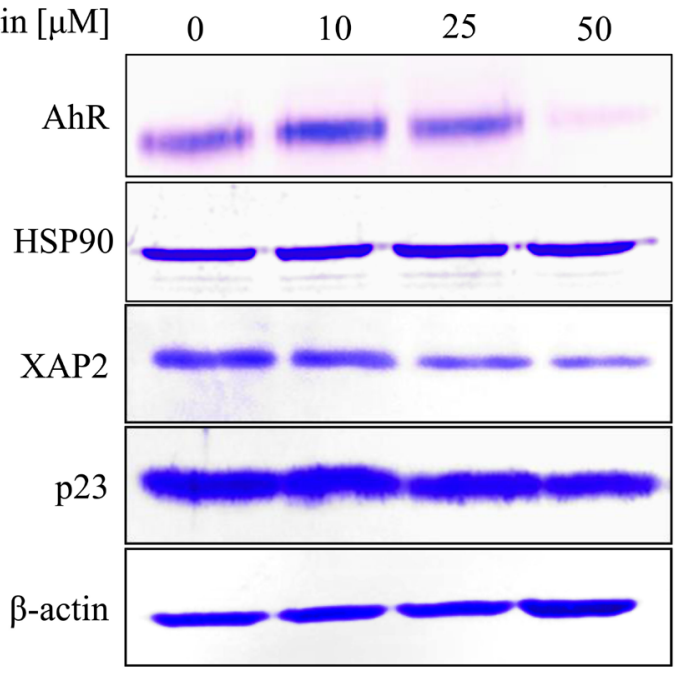

(b)

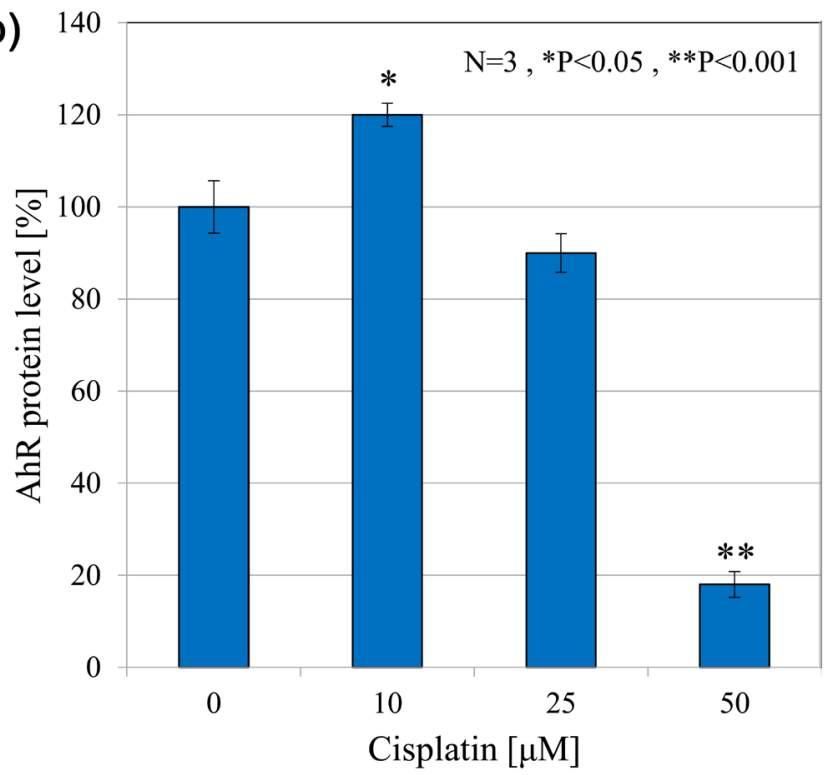

(c)

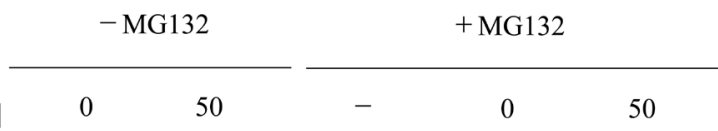

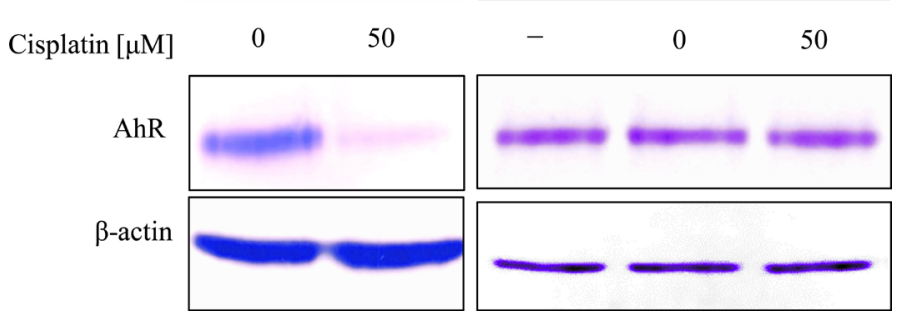

Figure 2. Effects of cisplatin on AhR. (a) HeLa cells were cultured in the presence or absence of cisplatin $(10,25$, and $50 \mu \mathrm{M})$ for $16 \mathrm{hrs}$. The HeLa cell lysates were analyzed by SDS-PAGE following immunoblotting using antibodies against AhR, HSP90, XAP2, p23, and $\beta$-actin. The AhR protein level based on (a) was quantified using Image $\mathrm{J}$ software (b). (c) HeLa cells were cultured in the presence or absence of $50 \mathrm{mM}$ cisplatin for $16 \mathrm{hrs}$ and $50 \mu \mathrm{M}$ MG132 added for more than $1 \mathrm{hr}$. The HeLa cells lysate were analyzed by SDS-PAGE following immunoblotting using antibodies against AhR and $\beta$-actin. 


\subsection{Effects of Cisplatin on AhR Activation}

We next investigated CYP1A1 expression level. Cyp1A1 mRNA was analyzed by RT-PCR in the absence (Figure 3(a)) or presence of 3MC (Figure 3(b)) from 0 to $8 \mathrm{hrs}$. CYP1AI was increased from $2 \mathrm{hrs}$ and the maximum occurred at $4 \mathrm{hr}$ (Figure 3(b)). We next analyzed the influence of cisplatin on the CYP1A1 expression. In the presence of $3 \mathrm{MC}$, the indicated cisplatin was added to the HeLa cells and the CYP1A1 mRNA was analyzed by RT-PCR and agarose gel electrophoresis (Figure $3(\mathrm{c})$ ). The CYP1A1/ $\beta$-actin ratio based on Figure $3(\mathrm{c})$ was quantified. At $50 \mu \mathrm{M}$ cisplatin, the CYP1A mRNA level was low until about 20\% (Figure 3(d)).

\subsection{Influence of ATP, Cisplatin, and 17-DMAG on AhR-HSP90 Complex}

We investigated the GST pull-down assay using GST-bHLH and HSP90. GST pull-down assay was performed in the presence or absence of $50 \mu \mathrm{M}$ cisplatin, 50
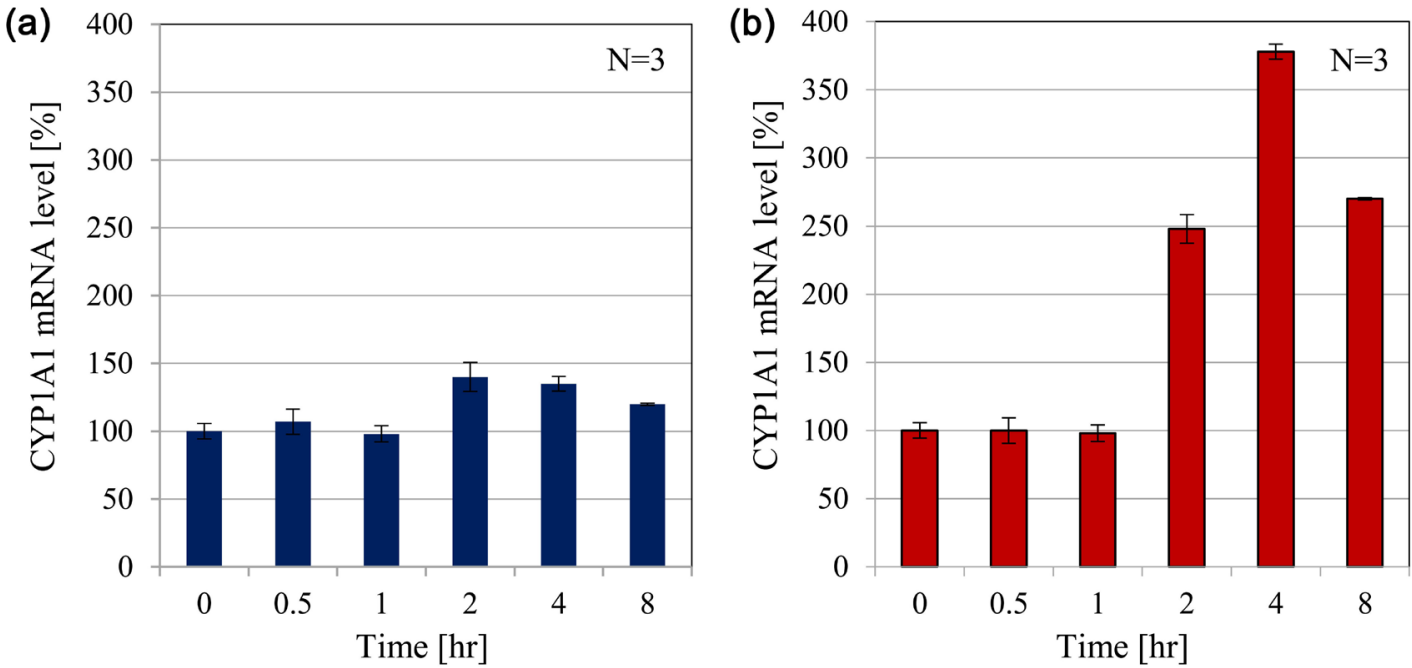

(c)

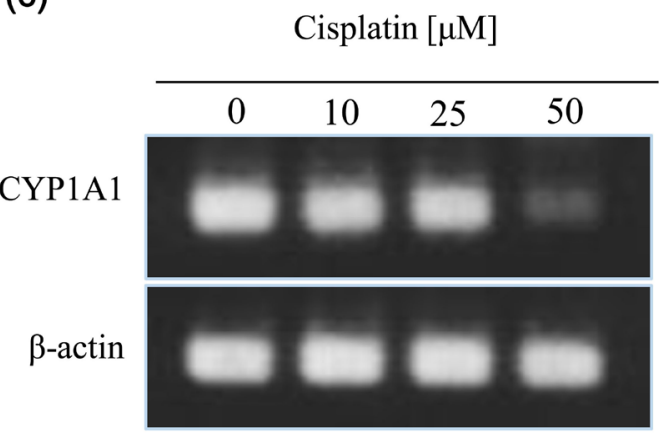

(d)

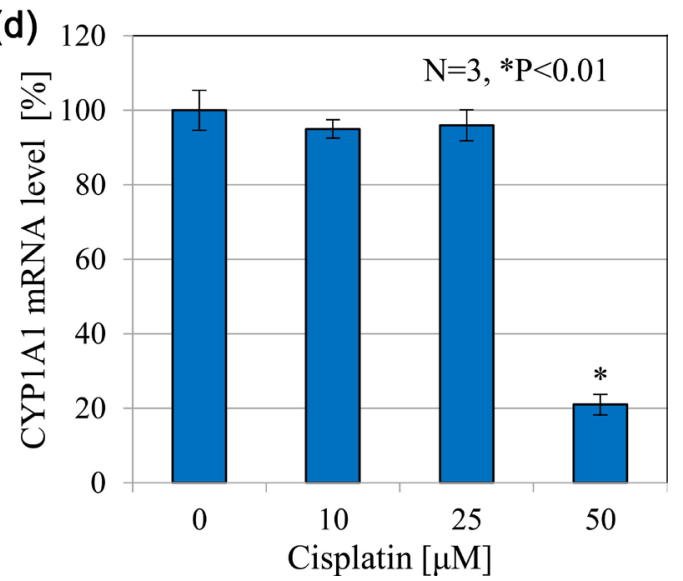

Figure 3. Effects of cisplatin on induction of CYP1A1. HeLa cells were cultured in the presence of $0.1 \%(\mathrm{v} / \mathrm{v})$ DMSO (a) or $3 \mu \mathrm{M} 3 \mathrm{MC}$ for $0,0.5,1,2,4$, and $8 \mathrm{hr}$ (b). CYP1A1 was investigated by RT-PCR. HeLa cells were cultured for 4 hrs in the absence or presence of cisplatin $(10,25$, and $50 \mu \mathrm{M})$ and CYP1A1 or $\beta$-actin was analyzed by RT-PCR (c). The CYP1A1/ $\beta$-actin ratio based on (d) was quantified using Image J software (c). 
$\mu \mathrm{M}$ 17-DMAG, and $1 \mathrm{mM}$ ATP [3] [4] [9] [10]. Although no HSP90 was bound to GST (Figure 4(a), left panel), GST-bHLH could bind to HSP90. For ATP and 17-DMAG, there were no effects on the association or dissociation between bHLH and HSP90. The HSP90 contents were also the same as the control (no ATP, cisplatin, and 17-DMAG). On the contrary, the bHLH bound HSP90 was less than that of HSP90. In the presence of cisplatin, no effects were observed during the association or dissociation of bHLH and HSP90. Based on the GSTbHLH-HSP90 pull-down assay, there were no effects of ATP or 17-DMAG, and ATP/17-DMAG on the GST bHLH-HSP90 association or dissociation (Figure 4 (a), right panels). Next, we confirmed the influence of the ligand on the AhRHSP90 complex using GST-AhR- $\triangle \mathrm{AD}$. AhR- $\triangle \mathrm{AD}$ is near the full length of AhR (deletion of transactivation domain). As shown in Figure 4(b), no changes in the GST-AhR- $\triangle \mathrm{AD}$ and HSP90 ratio in the absence or presence of $3 \mathrm{MC}$ were observed. As shown in Figure 4(c), GST-AhR- $\triangle$ AD could bind to HSP90 in the presence of 3MC. ATP had no effect on the ratio of GST-AhR- $\triangle A D$ and HSP90. HSP90 was dissociated from GST-AhR- $\triangle \mathrm{AD}$ when in the presence of cisplatin (Figure 4(c), lanes 3 and 4 from the right). Although ligand (3-MC), ATP, and 17-DMAG had no influence on the AhR-HSP90 complex, only cisplatin promote dissociation of AhR from HSP90.

\section{Discussion}

It has been reported that AhR is composed of three domains (b-HLH, PAS, and TAD; transactivation domains) [14] [15] [16]. AhR forms a complex with the molecular chaperone HSP90, co-chaperone p23, and the hepatitis B virus $\mathrm{X}$-associated protein XAP2 in the cytoplasm [14] [15] [16]. The molecular chaperone HSP90 regulates the physiological functions of more than 300 proteins including the steroid hormone receptors in the cells [1] [2]. We reported the activation mechanisms of AHR by HSP90 [9]. We also reported that AhR binds to the HSP90 N-domain [10]. We speculated that the bHLH binding site of the HSP90 N-domain may be the neighbor of the M-domain. On the contrary, the PAS binding site of the HSP90 N-domain may be the end of the N-domain.

In the present study, we investigated the influence of cisplatin on the AhR activation. We reported that cisplatin binds to HSP90 and inhibits HSP90 chaperone activity [3] [4]. Cisplatin binds to the HSP90 C-domain following the $\mathrm{N}$-domain. The AhR contents in the HeLa cells were strongly reduced in the presence of $50 \mu \mathrm{M}$ cisplatin at $16 \mathrm{hrs}$ after addition of the drug. However, we could detect AhR in the presence of MG132 during immunoblotting. AhR plays the role as a transcription factor in the nuclei and induces CYP1A1 [17]. In the presence of $50 \mu \mathrm{M}$ cisplatin, the CYP1A1 mRNA level was strongly reduced. These results suggested that AhR was dissociated from the HSP90 chaperone complex when in the presence of cisplatin. AhR is a very unstable protein, thus the released unstable AhR will be degraded through the $26 \mathrm{~S}$ proteasome.

It is difficult to purify the full length AhR because of its unstability. The 


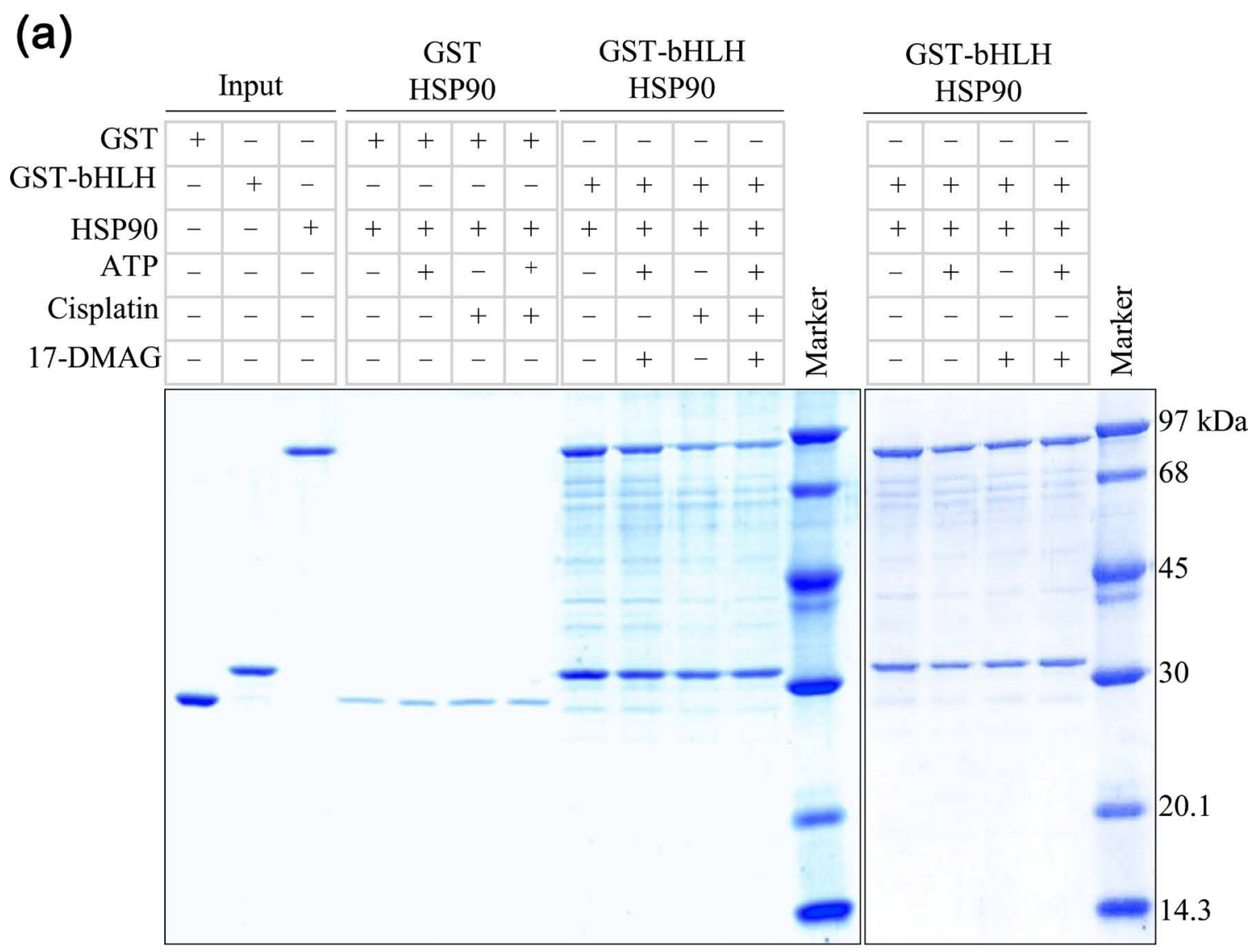

(b)

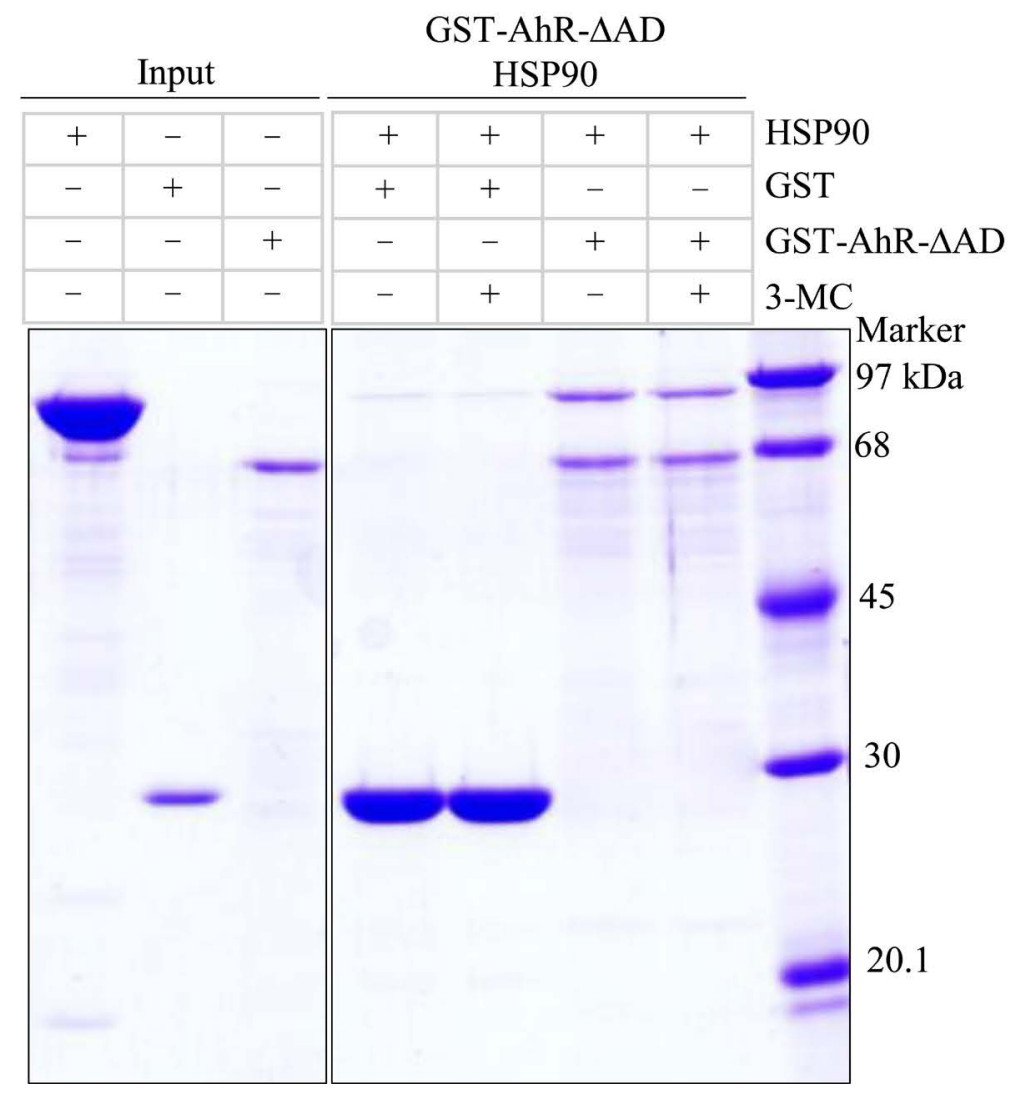


(c)

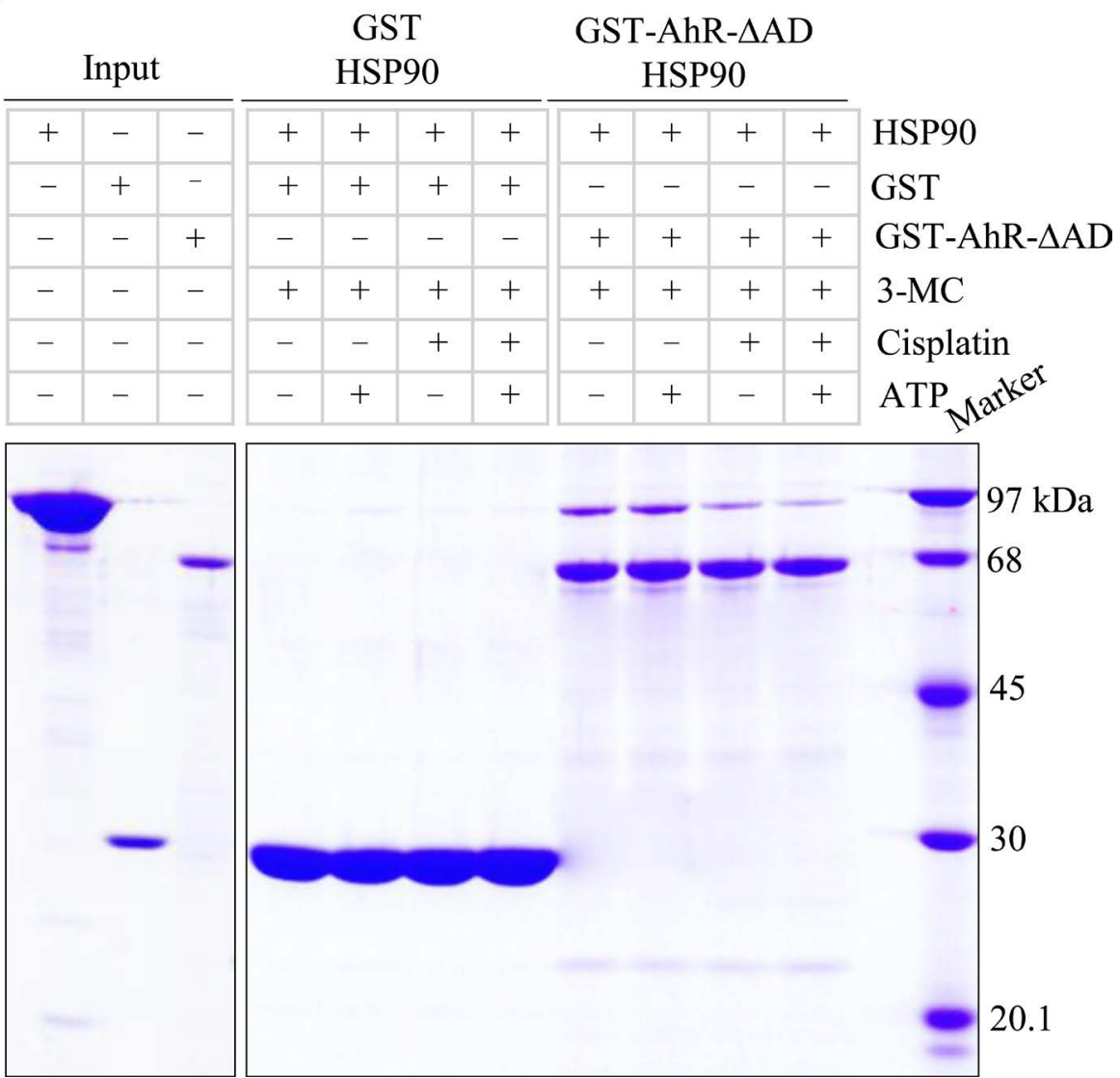

Figure 4. GST pull-down assay. (a) GST pull-down assays were investigated in the presence of $50 \mu \mathrm{M}$ cisplatin or $50 \mu \mathrm{M}$ 17-DMAG and $1 \mathrm{mM}$ ATP using GST-bHLH and HSP90 on SDSPAGE (11\% gel). (b) GST pull-down assays were analyzed using GST or GST-AhR- $\triangle \mathrm{AD}$ and HSP90 in the presence or absence of $3 \mu \mathrm{M} 3 \mathrm{MC}$ on SDS-PAGE (9\% gel). (c) GST pull-down assays were analyzed using GST or GST-AhR- $\mathrm{AD}$ and HSP90 in the presence or absence of 3 $\mu \mathrm{M} 3 \mathrm{MC}, 50 \mu \mathrm{M}$ cisplatin and $1 \mathrm{mM}$ ATP on SDS-PAGE (9\% gel).

Q-rich transactivation domain of AhR is toxic to E. coli. We investigated the influence of cisplatin and 17-DMAG (both compounds are HSP90 inhibitors) on the bHLH-HSP90 complex using a pull-down assay. No changes were shown in 17-DMAG in the presence or absence of ATP. On the other hand, the bHLH bound HSP90 was reduced by cisplatin. We reported that AhR-bHLH is also the HSP90 binding domain, the same as the AhR-Pas domain [10]. We investigated the influence of cisplatin on the ligand-bound AhR-HSP90 using AhR- $\triangle A D$. AhR- $\triangle \mathrm{AD}$ includes bHLH and the PAS domain. Cisplatin affected the ligandbound AhR-HSP90. As shown in Figure 4(c), cisplatin dissociated the HSP90 form the ligand-bound AhR- $\triangle \mathrm{AD}$.

In our present study, 17-DMAG didn't affect the AhR-HSP90 complex in the presence or absence of ATP. However, cisplatin affects the AhR-HSP90 complex. Based on these results, AhR may bind to the HSP90 N-domain, the cisplatin binding site, but not the ATP-binding site. Although 17-DMAG has no effect on the AhR activation, cisplatin inhibits the AhR activation. This is a first report of 
the influence of cisplatin to AhR-HSP90 co-chaperone complex.

AhR agonists affect several key players in EMT, such as JNK, Slug and NFAT, thereby leading to loss of E-cadherin function, which supports a role of the AhR in tumor progression. AhR-dependent tumor promoters might be powerful tumorigenic agents because they have the capability to enhance fixation of any DNA damage, expansion of initiated cells, i.e. tumor promotion and finally to drive progression [8]. Patients who are taking anti-cancer drugs cisplatin may not be able to expect drug metabolism against aromatic hydrocarbon-based poisons.

\section{Conflict of Interest}

The authors declare no conflict of financial interests.

\section{References}

[1] Schopf, F.H., Biebl, M.M. and Buchner, J. (2017) The HSP90 Chaperone Machinery. Nature Reviews Molecular Cell Biology, 18, 345-360. https://doi.org/10.1038/nrm.2017.20

[2] Sahasrabudhe, P., Rohrberg, J., Biebl, M.M., Rutz, D.A. and Buchner, J. (2017) The Plasticity of the Hsp90 Co-Chaperone System. Molecular Cell, 67, 947-961.

[3] Itoh, H., Ogura, M., Komatsuda, A., Wakui, H., Miura, A.B. and Tashima, Y. (1999) A Novel Chaperone-Activity-Reducing Mechanism of the $90-\mathrm{kDa}$ Molecular Chaperone HSP90. The Biochemical Journal, 343, 697-703. https://doi.org/10.1042/bj3430697

[4] Ishida, R., Takaoka, Y., Yamamoto, S., Miyazaki, T., Otaka, M., Watanabe, S., Komatsuda, A., Wakui, H., Sawada, K., Kubota, H. and Itoh, H. (2008) Cisplatin Differently Affects Amino Terminal and Carboxyl Terminal Domains of HSP90. FEBS Letters, 582, 3879-3883. https://doi.org/10.1016/j.febslet.2008.10.029

[5] Henry, E.C. and Gasiewicz, T.A. (1993) Transformation of the Aryl Hydrocarbon Receptor to a DNA-Binding Form Is Accompanied by Release of the $90 \mathrm{kDa}$ Heat-Shock Protein and Increased Affinity for 2,3,7,8-Tetrachlorodibenzo-p-Dioxin. The Biochemical Journal, 294, 95-101. https://doi.org/10.1042/bj2940095

[6] Hollingshead, B.D., Petrulis, J.R. and Perdew, G.H. (2004) The Aryl Hydrocarbon (Ah) Receptor Transcriptional Regulator Hepatitis B Virus X-Associated Protein 2 Antagonizes p23 Binding to Ah Receptor-Hsp90 Complexes and Is Dispensable for Receptor Function. The Journal of Biological Chemistry, 279, 45652-45661. https://doi.org/10.1074/jbc.M407840200

[7] Nukaya, M., Lin, B.C., Glover, E., Moran, S.M., Kennedy, G.D., Bradfield, C.A., Nukaya, M., Lin, B.C., Glover, E., Moran, S.M., Kennedy, G.D. and Bradfield, C.A. (2010) The Aryl Hydrocarbon Receptor-Interacting Protein (AIP) Is Required for Dioxin-Induced Hepatotoxicity But Not for the Induction of the Cypla1 and Cyp1a2 Genes. The Journal of Biological Chemistry, 285, 35599-35605. https://doi.org/10.1074/jbc.M110.132043

[8] Dietrich, C. and Kaina, B. (2010) The Aryl Hydrocarbon Receptor (AhR) in the Regulation of Cell-Cell Contact and Tumor Growth. Carcinogenesis, 31, 1319-1328. https://doi.org/10.1093/carcin/bgq028

[9] Tsuji, N., Fukuda, K., Nagata, Y., Okada, H., Haga, A., Hatakeyama, S., Yoshida, S., Okamoto, T., Hosaka, M., Sekine, K., Ohtaka, K., Yamamoto, S., Otaka, M., Grave, 
E. and Itoh, H. (2014) The Activation Mechanism of the Aryl Hydrocarbon Receptor (AhR) by Molecular Chaperone HSP90. FEBS Open Bio., 4, 796-803. https://doi.org/10.1016/j.fob.2014.09.003

[10] Kudo, I., Hosaka, M., Haga, A., Tsuji, N., Nagata, Y., Okada, H., Fukuda, K., Kakizaki, Y., Okamoto, T., Grave, E. and Itoh, H. (2017) The Regulation Mechanisms of AhR by Molecular Chaperone Complex. The Journal of Biochemistry. (In Press) https://doi.org/10.1093/jb/mvx074

[11] Murray, I.A., Patterson, A.D. and Perdew, G.H. (2014) Aryl Hydrocarbon Receptor Ligands in Cancer: Friend and Foe. Nature Reviews Cancer, 14, 801-814. https://doi.org/10.1038/nrc3846

[12] Wang, H., Wei, Y. and Yu, D. (2015) Control of Lymphocyte Homeostasis and Effector Function by the Aryl Hydrocarbon Receptor. International Immunopharmacology, 28, 818-824. https://doi.org/10.1016/j.intimp.2015.03.046

[13] Rosenhagen, M.C., Soti, C., Schmidt, U., Wochnik, G.M., Hartl, F.U., Holsboer, F., Young, J.C. and Rein, T. (2003) The Heat Shock Protein 90-Targeting Drug Cisplatin Selectively Inhibits Steroid Receptor Activation. Molecular Endocrinology, 17, 1991-2001. https://doi.org/10.1210/me.2003-0141

[14] Lindebro, M.C., Poellingerl, L. and Whitelawl, M.L. (1995) Protein-Protein Interaction via PAS Domains: Role of the PAS Domain in Positive and Negative Regulation of the HLH/PAS Dioxin Receptor-Arnt Transcription Factor Complex. The EMBO Journal, 14, 3528-3539.

[15] Kewley, R.J., Whitelaw, M.L. and Chapman-Smith, A. (2004) The Mammalian Basic Helix-Loop-Helix/PAS Family of Transcriptional Regulators. The International Journal of Biochemistry \& Cell Biology, 36, 189-204. https://doi.org/10.1016/S1357-2725(03)00211-5

[16] Mimura, J. and Fujii-Kuriyama, Y. (2003) Functional Role of AhR in the Expression of Toxic Effects by TCDD. Biochimica et Biophysica Acta, 1619, 263-268. https://doi.org/10.1016/S0304-4165(02)00485-3

[17] Beischlag, T.V., Luis Morales, J., Hollingshead, B.D. and Perdew, G.H. (2008) The Aryl Hydrocarbon Receptor Complex and the Control of Gene Expression. Critical Reviews $^{\text {Tm }}$ in Eukaryotic Gene Expression, 18, 207-250. https://doi.org/10.1615/CritRevEukarGeneExpr.v18.i3.20 


\section{Abbreviations}

AhR, aryl hydrocarbon receptor;

HSP90, 90-kDa of heat shock protein;

bHLH, basic helix-loop-helix;

PAS, per-arnt-sim;

TCDD, 2,3,7,8-tetrachlorodibenzo-p-dioxin;

3MC, 3-Methylcholanthrene;

CYP1A1, cytochrome P450 1A1;

GST, glutathione S-transferase;

IPTG, Isopropyl-1-thio- $\beta$-D-galactopyranoside;

17-DMAG, 17-(dimethylaminoethylamino)-17-demethoxygeldanamycin;

MG132 (N-carbobenzoxyl-Leu-Leu-leucinal). 